\title{
IPTEKS NILAI WAKTU UANG DAN IMPLIKASI PENCATATAN AKUNTANSI
}

\author{
Novi Swandari Budiarso ${ }^{1}$ \\ ${ }^{1}$ Program Studi Pendidikan Profesi Akuntansi, Fakultas Ekonomi dan Bisnis, Universitas Sam Ratulangi, Jl. \\ Kampus Bahu, Manado, 95115, Indonesia \\ E-mail : novi.sbudiarso@unsrat.ac.id
}

\begin{abstract}
Most of general public and firms know about money and its value but do not have better understanding how the money creates its own value relates to interest rate. Another side, most of firms still not realize that the time value of money has an impact on accounting recording and its reporting in financial statements, such as statement of financial position (balance sheet), income statement, and statement of cash flows.
\end{abstract}

Keywords : time value of money, accounting, future value, present value

\section{PENDAHULUAN}

Uang telah dikenal sejak lama oleh masyarakat dan digunakan sebagai alat tukar barang. Saat ini manfaat uang telah berkembang dengan luas selain sebagai alat tukat barang juga sebagai alat penukar jasa atau mata uang asing. Seiring dengan perkembangan teknologi, uang secara keseluruhan tidak lagi beredar secara fisik akan tetapi lebih banyak bergerak atau berpindah nilai secara elektronik. Masyarakat terlebih pihak perusahaan secara umum telah mengetahui jenis-jenis uang dan nilai yang melekat pada uang tersebut. Selain itu, masyarakat umum juga telah memiliki literasi atas keterkaitan uang dengan tingkat suku bunga yang berlaku.

Permasalahan umum yang terjadi adalah masyarakat atau perusahaan kurang memahami proses penghitungan nilai waktu uang yang memberikan estimasi atas nilai uang tersebut. Secara spesifik, dalam pengambilan keputusan, teknis pencatatan akuntansi, dan pelaporan keuangan, perusahaan sering mengabaikan nilai waktu uang karena pertimbangan konservatisme sehingga nilai historis uang tetap dipertahankan. Berdasarkan latar masalah diatas maka penerapan ipteks bertujuan untuk memberikan pengetahuan teknis tentang penghitungan nilai waktu uang dan implikasi terhadap pencatatan dan pelaporan akuntansi.

\section{TINJAUAN PUSTAKA}

Menurut Warren et al. (2009), Garrison et al. (2010), dan Kieso et al. (2013), dalam bidang akuntansi atau keuangan, istilah "nilai waktu uang" atau "time value of money" mengindikasikan hubungan antara waktu dan uang, sehingga setiap sen dari mata uang yang diterima pada waktu sekarang dianggap lebih bernilai dibandingkan dengan setiap sen dari mata uang yang akan diterima di masa yang kan datang. Kimmel et al. (2011), dan Libby et al. (2011) menambahkan bahwa faktor-faktor yang mempengaruhi konsep nilai waktu uang adalah nilai uang itu sendiri, jangka waktu, dan tingkat bunga. Menurut Kieso et al. (2013), kondisi ini lebih banyak disebabkan karena adanya peluang atas investasi masa kini dan bunga yang diterima atas investasi yang dilakukan. Blocher et al. (2010) menegaskan bahwa nilai sekarang dari arus kas masa depan adalah nilai ekuivalen dari nilai uang itu sendiri pada masa sekarang atau disebut nilai uang yang disesuaikan dengan waktu (time-adjusted value).

Brigham dan Houston (2009), Horngren et al. (2012), dan Kieso et al. (2013) mengemukakan konsep bahwa nilai sekarang (present value) dari uang akan selalu memiliki nilai yang lebih kecil daripada nilai masa depan (future value) yang diketahui terkait dengan akumulasi tingkat bunga. Menurut Bodie et al. (2009) tingkat bunga dalam sebuah periode 
sering berbeda untuk mengakrualkan nilai uang pada periode yang berbeda. Atrill dan McLaney (2006), Pike dan Neale (2009), dan Parrino et al. (2012) mengilustrasikan bahwa nilai uang sekarang dari sebuah investasi akan memiliki nilai uang yang lebih kecil dibandingkan dengan nilai uang yang akan diterima pada masa yang akan datang.

\section{METODE DAN TEKNIK PENERAPAN IPTEKS}

\subsection{Metode Penerapan Ipteks}

Penerapan ipteks ditempuh dengan memberikan contoh kasus penghitungan nilai waktu uang dengan menggunakan future value dan present value.

\subsection{Teknik Penerapan Ipteks}

Teknik yang digunakan untuk penerapan ipteks adalah melakukan penghitungan nilai waktu uang berdasarkan future value dan present value dan memberikan contoh transaksi umum yang sering digunakan dalam pencatatan akuntansi.

\section{PEMBAHASAN}

\subsection{Gambaran Objek Penerapan Ipteks}

Objek atas penerapan ipteks adalah masyarakat secara umum, usaha kecil menengah, dan atau perusahaan secara umum yang melaksanakan pencatatan dan pelaporan akuntansi atas kegiatan usahanya.

\subsection{Pembahasan}

Mengacu pada konsep Kieso et al. (2013), maka pemahaman atas konsep nilai waktu uang akan diawali dengan konsep waktu dimana posisi uang tersebut berada. Dalam pemahaman konsep ini, istilah nilai uang waktu sekarang (present value) disimbolkan dengan $\mathrm{PV}$, nilai uang waktu yang akan datang (future value) disimbolkan dengan FV, periode waktu (time) disimbolkan dengan $\mathrm{t}$, dan tingkat bunga (interest rate) disimbolkan dengan i. Gambar 1 mengilustrasikan bahwa, nilai uang saat ini adalah Rp. 10.000 yang akan dhitung nilainya pada akhir tahun ke 3, dimana tingkat bunga konstan yang berlaku adalah $10 \%$.

\begin{tabular}{|l|l|lc|}
$\mathrm{PV}=$ Rp. 10.000 & $\mathrm{FV}=2$ & $\mathrm{t}=3$ \\
& & $\mathrm{FV}_{2}=?$ & $\mathrm{FV}_{3}=?$ \\
\hline & & &
\end{tabular}

\section{Gambar 1. Konsep nilai uang dimasa depan (future value)}

Jika diasumsikan bahwa nilai uang yang akan diketahui adalah pada akhir tahun pertama $(\mathrm{t}=1)$, maka langkah-langkah yang akan ditempuh adalah :

$$
\begin{array}{rllc}
\mathrm{FV}_{1} & =\text { Rp. } 10.000 & \mathrm{x} & (1+10 \%)^{1} \\
& =\text { Rp. } 10.000 & \mathrm{x} & (1+0.1)^{1} \\
& \text { Rp. } 10.000 & \mathrm{x} & 1.1 \\
& =\text { Rp. } 11.000 & &
\end{array}
$$

Jika diasumsikan bahwa nilai yang akan dihitung adalah nilai uang pada akhir tahun ke 2, maka penghitungan yang ditempuh adalah :

$$
\begin{aligned}
& \mathrm{FV}_{2}=\text { Rp. } 10.000 \times(1+10 \%)^{2} \\
& =\text { Rp. } 10.000 \times(1+0.1)^{2} \\
& =\text { Rp. } 10.000 \mathrm{x} \quad 1.21 \\
& =\text { Rp. } 12.100
\end{aligned}
$$


Jika diasumsikan bahwa nilai yang akan dihitung adalah nilai uang pada akhir tahun ke 3, maka penghitungan yang ditempuh adalah :

$$
\begin{array}{rlrc}
\mathrm{FV}_{3} & =\text { Rp. } 10.000 \text { x } & (1+10 \%)^{3} \\
& =\text { Rp. } 10.000 \text { x } & (1+0.1)^{3} \\
& =\text { Rp. } 10.000 \text { x } & 1.331 \\
& =\text { Rp. } 13.310
\end{array}
$$

Implikasi pada pencatatan akuntansi dapat diilustrasikan sebagai berikut, jika diasumsikan sebuah perusahaan melakukan penjualan kredit sebesar Rp. 10.000 pada 1 Januari 2018 dan dilunasi pada 1 Januari 2019, maka catatan yang diperlukan adalah :

1 Januari 2018 Piutang dagang $\quad 10.000$

Pendapatan Penjualan $\quad 10.000$

1 Januari 2019 Kas
10.000

$$
\text { Piutang dagang } \quad 10.000
$$

Apabila pencatatan akuntansi diatas dikaitkan dengan nilai wajar dari uang, dimana tingkat bunga yang berlaku sepanjang tahun 2018 adalah sebesar 10\%, maka dapat diasumsikan bahwa perusahaan mengalami kerugian sebesar Rp. 1.000 atau Rp. 11.000 (nilai uang waktu masa depan) dikurangi Rp. 10.000 (nilai uang waktu sekarang). Nilai kerugian yang diestimasi akan semakin besar apabila piutang dagang yang dimaksud memiliki jangka waktu ketertagihan yang lebih lama.

Permasalahan kasus diatas akan memiliki hasil yang sama apabila menggunakan konsep uang masa sekarang (present value). Gambar 2 mengilustrasikan bahwa, nilai uang masa depan adalah Rp. 11.000, Rp. 12.100, dan Rp. 13.310 yang akan dhitung nilainya pada tahun sekarang, dimana tingkat bunga konstan yang berlaku adalah $10 \%$.

\begin{tabular}{|l|l|lr|}
$\mathrm{PV}=?$ & $\mathrm{t}=1$ & $\mathrm{t}=2$ & $\mathrm{t}=3$ \\
$\mathrm{FV}$ & $\mathrm{FV} \mathrm{R}_{1}=\mathrm{Rp} .11 .000$ & $\mathrm{FV}_{2}=12.100$ & $\mathrm{FV}_{3}=13.310$ \\
\hline & $\mathrm{i}=10 \%$ &
\end{tabular}

\section{Gambar 2. Konsep nilai uang masa sekarang (present value)}

Jika diasumsikan bahwa nilai uang yang diketahui pada akhir tahun pertama $(\mathrm{t}=1)$ adalah sebesar Rp. 11.000, maka langkah-langkah yang akan ditempuh adalah :

$$
\begin{aligned}
\mathrm{PV}_{1} & =\text { Rp. } 11.000 \times \frac{1}{(1+10 \%)^{1}} \\
& =\text { Rp. } 11.000 \times 0.909091 \\
& =\text { Rp. } 10.000
\end{aligned}
$$

Jika diasumsikan bahwa nilai uang yang diketahui pada akhir tahun kedua ( $\mathrm{t}=2)$ adalah sebesar Rp. 12.100, maka langkah-langkah yang akan ditempuh adalah : 


$$
\begin{aligned}
\mathrm{PV}_{2} & =\text { Rp. } 12.100 \times \frac{1}{(1+10 \%)^{2}} \\
& =\text { Rp. } 12.100 \times 0.826446 \\
& =\text { Rp. } 10.000
\end{aligned}
$$

Jika diasumsikan bahwa nilai uang yang diketahui pada akhir tahun ketiga $(\mathrm{t}=3)$ adalah sebesar Rp. 13.310, maka langkah-langkah yang akan ditempuh adalah :

$$
\begin{aligned}
\mathrm{PV}_{2} & =\text { Rp. } 13.310 \times \frac{1}{(1+10 \%)^{3}} \\
& =\text { Rp. } 13.310 \times 0.751315 \\
& =\text { Rp. } 10.000
\end{aligned}
$$

Konsep nilai waktu uang berdasarkan pendekatan nilai uang pada waktu sekarang memberikan implikasi yang sama pada pencatatan akuntansi terkait dengan nilai wajar dari uang tersebut. Pendekatan nilai uang waktu yang akan datang (future value) dan pendekatan nilai uang waktu sekarang (present value) juga memiliki implikasi yang sama apabila diterapkan dalam konteks keputusan investasi.

\section{KESIMPULAN DAN SARAN}

\subsection{Kesimpulan}

Pendekatan nilai uang waktu yang akan datang (future value) dan pendekatan nilai uang waktu sekarang (present value) memiliki implikasi yang signifikan terhadap pencatatan dan pelaporan akuntansi terkait nilai wajar dari uang. Hasil penghitungan menurut konsep nilai uang waktu yang akan datang (future value) dan konsep nilai uang waktu sekarang (present value) menunjukkan bahwa ketidaktepatan atas keputusan estimasi nilai uang akan mengakibatkan tidak tepatnya pencatatan akuntansi dan memberikan dampak rugi estimasi atas pelaporan keuangan.

\subsection{Saran}

Bagi masyarakat umum, agar dapat menjadikan ipteks nilai waktu uang sebagai referensi dalam pengambilan keputusan yang terkait dengan kehidupan sosialnya. Bagi perusahaan termasuk usaha kecil dan menengah, agar dapat menjadikan konsep nilai waktu uang yang mencerminkan nilai wajar uang tersebut sebagai dasar pengambilan keputusan yang dapat mempengaruhi keputusan dalam hal pencatatan dan pelaporan akuntansi. Walaupun nilai uang yang dihasilkan dari kedua konsep ini bersifat estimasi atau tidak riil untuk dilaporkan oleh pihak perusahaan kepada pihak publik, akan tetapi untuk kepentingan pengambilan keputusan internal, maka perusahaan sebaiknya mempertimbangkan penggunaan konsep nilai waktu uang dalam pencatatan akuntansi khususnys untuk kepentingan pelaporan akuntansi manajemennya.

\section{DAFTAR PUSTAKA}

Atrill, P., \& McLaney, E. (2006). Accounting and Finance for Non-Specialists. United Kingdom : Pearson Education Limited.

Blocher, E. J., Stout, D. E., \& Cokins, G. (2010). Cost Management : A Strategic Emphasis, $5^{\text {th }}$ Edition. New York : McGraw-Hill. 
Bodie, Z., Kane, A., \& Marcus, A. J. (2009). Investments, $8^{\text {th }}$ Edition. New York : McGrawHill, Irwin.

Brigham, E. F., \& Houston, J. F. (2009). Fundamentals of financial management, $12^{\text {th }}$ Edition. Mason : South-Western Cengage Learning.

Garrison, R. H., Noreen, E. W., \& Brewer, P. C. (2010). Managerial Accounting, $13^{\text {th }}$ Edition. New York : McGraw-Hill.

Horngren, C. T., Harrison Jr., W. T., \& Oliver, M. S. (2012). Accounting, $9^{\text {th }}$ Edition. New Jersey : Pearson Education, Inc.

Kieso, D. E., Weygandt, J. J., \& Warfield, T. D. (2013). Intermediate Accounting, $15^{\text {th }}$ Edition. New York : John Wiley \& Sons Inc.

Kimmel, P. D., Weygandt, J. J., \& Kieso, D. E. (2011). Accounting, $4^{\text {th }}$ Edition. New Jersey: John Wiley \& Sons, Inc.

Libby, R., Libby, P. A., \& Short, D. G. (2011). Financial Accounting, $7^{\text {th }}$ Edition. New York : McGraw-Hill Irwin.

Parrino, R., Kidwell, D. S., \& Bates, T. W. (2012). Fundamentals of corporate finance, $2^{\text {nd }}$ Edition. New Jersey: John Wiley \& Sons, Inc.

Pike, R., \& Neale, B. (2009). Corporate finance and investment : Decisions \& strategies, $6^{\text {th }}$ Edition. England : Pearson Education Ltd.

Warren, C. S., Reeve, J. M., \& Duchac, J. E.. (2009). Accounting, $23^{\text {rd }}$ Edition. Mason : South Western Cengage Learning. 